\title{
Experimental Study of the Influence of Shot Peening on the Microstructure and Properties of Surface Layer of a TC21 Titanium Alloy
}

\author{
Y. Song*, Z. Zhao, and F. Lu \\ Beijing Institute of Aeronautical Materials, Beijing 100095, P.R. China
}

Received: January 2, 2014 / Accepted: April 21, 2014

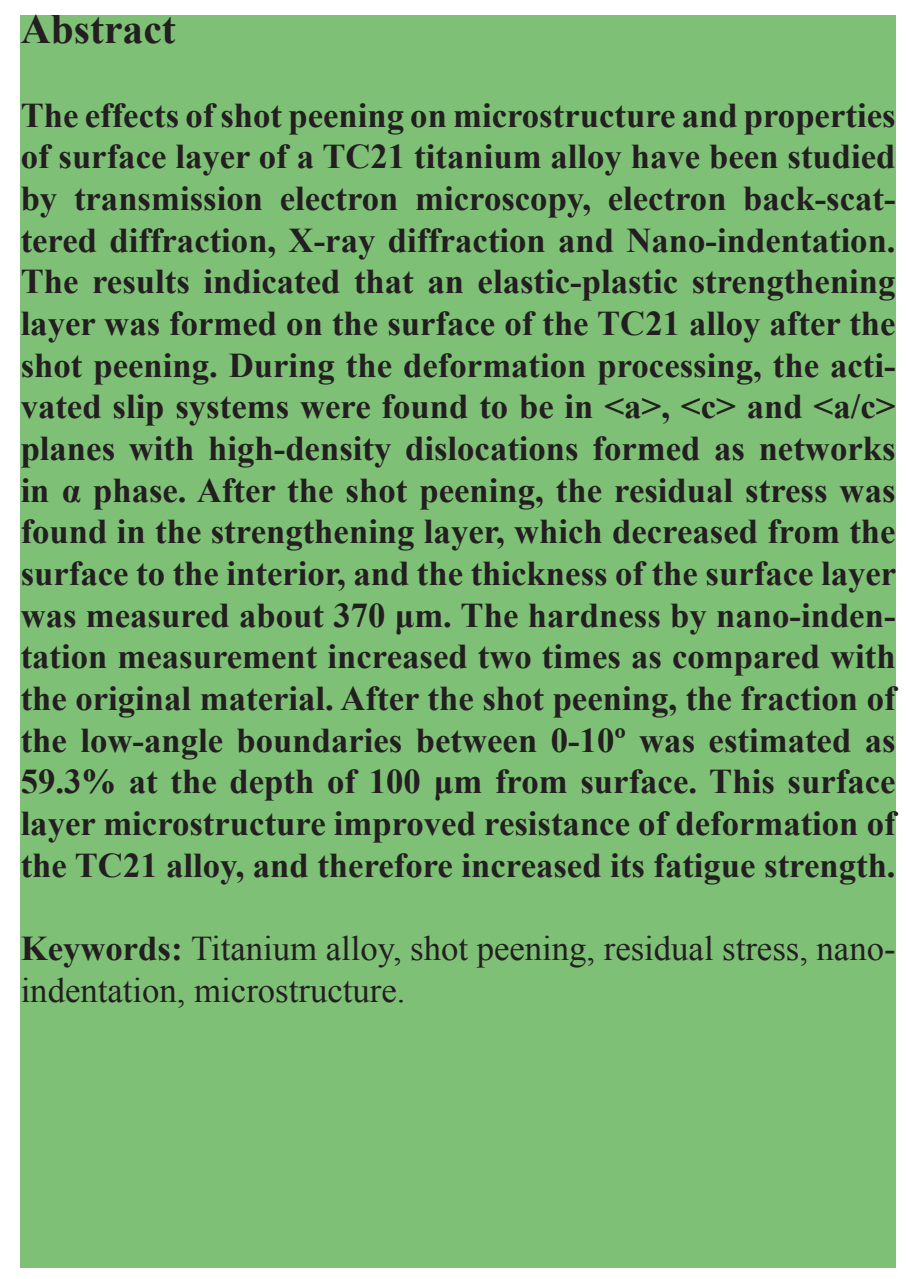

* Corresponding author: ygs2002cn@163.com

\section{Introduction}

TC21 alloy is a damage tolerance titanium alloy, which exhibits relatively high or moderate strength with higher fracture toughness and lower fatigue crack growth rate (Feng et al., 2004; Fei et al., 2008). Consequently, it has been considered as a structural material for aircraft applications recently. TC21 alloy is a new alpha-beta $(\alpha-\beta)$ alloy that belongs to the Ti-Al$\mathrm{Sn}-\mathrm{Zr}-\mathrm{Mo}-\mathrm{Cr}-\mathrm{Nb}-\mathrm{Si}$ system. The microstructure of this alloy after heat treated in the $(\alpha+\beta)$ region is mainly net-type structure. The $\alpha$ and $\beta$ phases have the crystallographic orientation relationship: $\{110\}_{\alpha} / /\{0001\}_{\beta},\{111\}_{\alpha} / /\{1120\}_{\beta}$, and $\{112\}_{\alpha} / /$ $\{1010\}_{\beta}$ (Ge et al., 2005).

For industrial applications, shot peening technique has been established to improve the fatigue properties of metallic materials for a long time. Due to its convenience in operation and favourable effects, shot peening has been widely used in the aerospace industry (Wang, 1979). Many researchers focus on steels (Shiozawa and $\mathrm{Lu}, 2002$ ), aluminum alloys (De Los Rios et al., 2000), magnesium alloys (Barry et al., 2009) and composite materials (Baragetti and Guagliano, 1998) treated by shot peening. In this process, the metal near the surface undergoes large plastic deformation due to the collision of large number of shots (Harada et al., 2007). Effects of the shot peening on the metals include surface integrity state which can be described by the residual stress field (Wang, 1979; Gao et al., 2003), surface roughness (Luong and Hill, 2010) and microstructure in the surface layer that influences the fatigue strength and lifetime (Tönshoff et al., 1997). For shot peened specimens, their surfaces show crater-like marks, which are typical repeated shot impacts, evidence of surface overlaps and sharp features that can serve as crack initiators (Luong and Hill, 2010). The sur- 
face profile line also shows the typical features of shot peening, including a large increase of roughness and irregular peaks and valleys (Luong and Hill, 2010). The residual stress profiles measured using hole drilling (Barry et al., 2009) and X-ray (Zhang and Liu, 2009) can provide the value on the surface, the maxima value in the layer and the depth of the stress. Moreover, research has been conducted to improve the fatigue property of titanium alloys by shot peening to increase the tolerance of the airplane components (Wagner, 1999; Wu et al., 2008). There are limited studies on the internal and subsurface microstructures of shot peened samples studied by transmission electron microscopy (TEM) (Yamamoto et al., 2006) and focused ion beam (FIB) (Okolo et al., 2007), and a few papers showing the profile of dislocation microstructure using the electron backscatter diffraction (EBSD) method.

This study aims to clarify the effect of shot peening on surface conditions, microstructure and properties of the TC21 alloy. In this investigation, the experimental data in the depth profiles of micro-hardness, dislocation densities and dislocation configurations were obtained through nano-indentation, EBSD and TEM. The mechanical surface strengthening mechanism of the TC21 alloy was discussed.

\section{Materials and Methods}

The material tested in this work was a TC21 titanium alloy, with chemical composition of Ti-6Al-2Sn-2Zr-3Mo-1Cr$2 \mathrm{Nb}$ (all wt.\%). Its tensile properties were tested as $1240 \mathrm{MPa}$ tensile strength, $1100 \mathrm{MPa}$ yield strength $(0.2 \%$ offset), $43 \%$ reduction in area and $18 \%$ elongation. The heat treatment processes were $910{ }^{\circ} \mathrm{C}$ for $1 \mathrm{~h} / \mathrm{AC}$ (air cooled) $+550{ }^{\circ} \mathrm{C}$ for $6 \mathrm{~h} / \mathrm{AC}$.

The shot peening was performed by means of an injector type system using cast steel shots, with an average diameter of $0.3 \mathrm{~mm}$. The Almen intensity $\left(f_{\mathrm{A}}\right)$ is $0.4 \mathrm{~mm}$, and the coverage of the peening procedure is $200 \%$ when the shot peening time is twice longer than the saturation time. The surface roughness of shot-peened specimen was measured by profilometry. Using an X-3000 X-ray diffractometer, residual stress was measured as a function of depth by $0-45^{\circ}$ four point method using Ti target. The diffract crystal plane was (213), and the peak positions were determined by a full width at half maximum (FWHM) technique. In order to obtain residual stress profiles, surface layers of specimen were removed step by step by electrolytic dissolution before measurement. The hardness of the samples along the cross section was conducted by Nano-indenter XP instrument, and the depth of the indentation was $400 \mathrm{~nm}$.

The sample for electron backscattering diffraction (EBSD) was cut from the shot peening specimens, with dimensions of about 10X10X5 $\mathrm{mm}^{3}$, prepared by electropolishing method. EBSD was performed using a JEOL JSM-6500F filed-emission scanning electron microscope (FE-SEM) operated at $30 \mathrm{kV}$. The corresponding data acquisition and processing were carried out using TSL software.

Samples for transmission electron microscopy (TEM) were cut from the surface of the shot peened specimen and then prepared by conventional method, including careful grinding (1200 grit) to produce a thin disc, followed with twin-jet elec- tropolishing for final thinning to reach electron transparency. The electrolyte used was a 34 vol.\% butyl alcohol +6 vol. $\%$ perchloric acid +60 vol. $\%$ methanol solution, cooled with liquid nitrogen to keep the temperature at $-15^{\circ} \mathrm{C}$. The TEM was undertaken using a JEOL 2010 TEM operated at $200 \mathrm{kV}$.

\section{Results}

In this investigation, we focus on the distribution of the residual stress, the microstructural change and the change of roughness in the surface layer.

\section{Surface Toughness and Topography}

Surface roughness and topography of a component have a considerable influence on the fatigue strength. High roughness values can cause micro-stress concentration and thus the loss of fatigue strength. Roughness measurements of the TC21 alloy after shot peening have been carried out. The average roughness value, $R_{\mathrm{a}}$, after shot peening up to a peening strength 0.4 A was about $1.482 \mu \mathrm{m}$, which was much greater than that of the untreated sample, $0.8 \mu \mathrm{m}$. Figure 1 shows the photographs of optical microscopy of the TC21 sample before (a) and after (b) shot peening. The unpeened specimen surface is relatively smooth, without significant mechanical flaws (Figure 1a). In the shot-peened specimen, the change of roughness and topography leaves a microcrater structure due to the impact of solid balls (Wagner, 1999). It is found at some locations of the surface, the diameter of microcraters reached about $200 \mu \mathrm{m}$. Traditionally, such surface discontinuities are regarded as potential fatiguecrack nucleation sites in the material. However, according to some investigations, cracks were never observed initiating from the surface in shot-peened samples (Jiang et al., 2007; Lindemann et al., 2006).

\section{Hardness Distribution}

Figure 2 indicates the distribution of nano-indentation hardness depth of the cross section of the TC21 alloy after shot peening. The typical load-depth $(F-h)$ curve, hardness and modulus curves are shown in Figure 2 (a), (b) and (c), respectively. After the shot peening treatment, the TC21 alloy has negligible changes of the modulus, but has a significant modification of
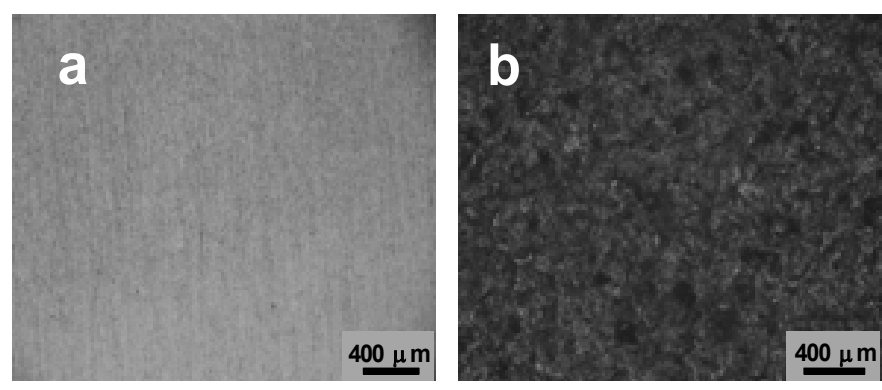

Figure 1. Topography of the TC21 alloy before (a) and after shot peening (b). 

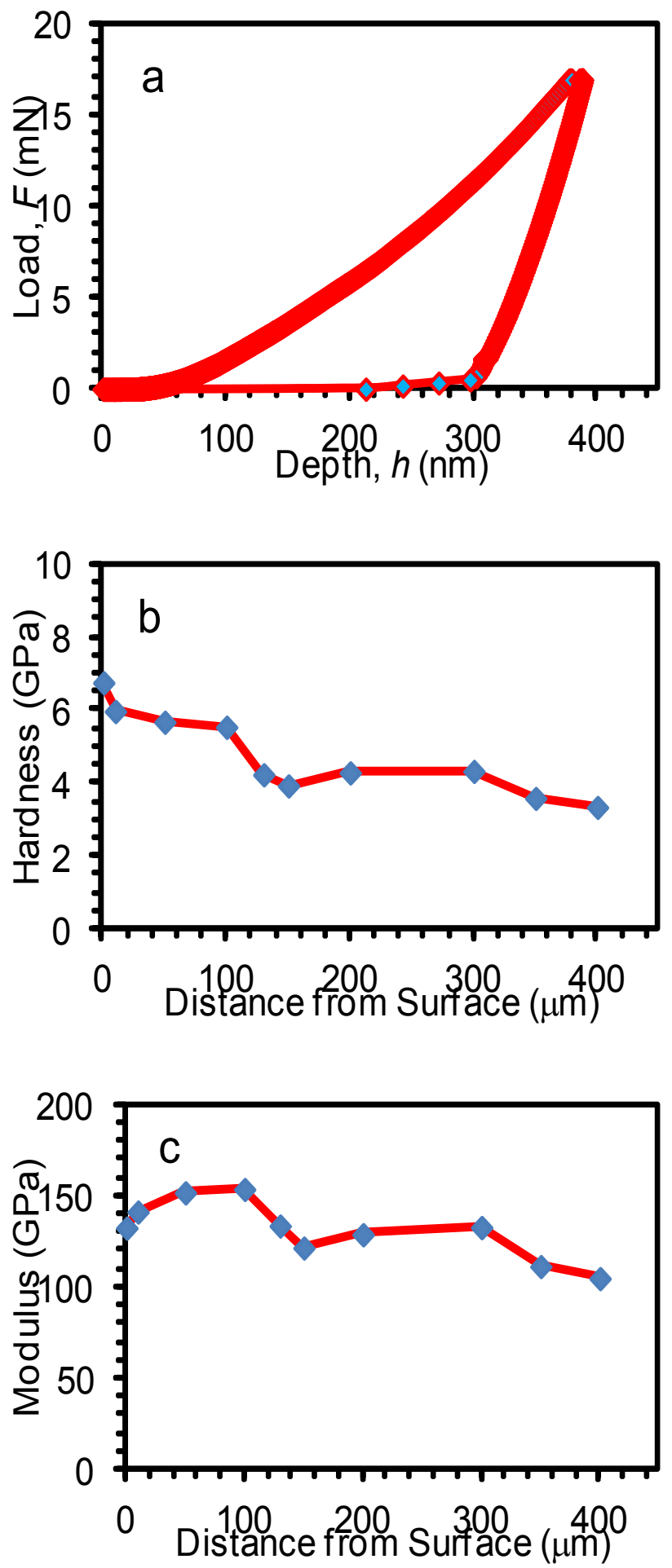

Figure 2. Evolution of the nanoindentation of the TC21 alloy after shot peening. (a) F- $h$ curve; (b) nanoindentation of hardness; (c) Young's modulus.

the hardness. After shot peening, the hardness increased about 2 times than that of the unpeened specimen. The hardness of the inner specimen is $3.2 \mathrm{GPa}$, while on the shot-penned surface, 6.7 GPa (Figure 2b). The depth of the layer is roughly $0.37 \mathrm{~mm}$. This can be explained by the modification of the structure near the surface caused by the shot peening.

\section{Residual Stress Distribution}

The reason for improving the fatigue life lies in the stressinduced transformation caused by the modification of the microstructure of the surface. Figure 3(a) shows the effect of shot peening on residual stress profiles along the depth from the surface of the TC21 alloy. The results show that a deformed layer with residual stress on the sample surface is formed after shot peening. In this investigation, using a shot peening of $0.4 \mathrm{~A}$, the stress of the surface is $-529.3 \mathrm{MPa}$, and the compressive residual stress reached the maximum of $-903.5 \mathrm{MPa}$ at the thickness about $0.13 \mathrm{~mm}$ below the surface. The depth of the deformed layer with compressive residual stress is $0.37 \mathrm{~mm}$, which is similar to the hardness result. Beyond $0.37 \mathrm{~mm}$, the stress becomes tensile stress. In addition to compressive residual stress, shot peening also generate significant change of the dislocation density, which is indicated by the FWHM of X-ray diffraction (XRD) peak, as determined by X-ray peak broadening (Figure 3b). The FWHM values, up to 3.8, were measured in the surface of the sample, whereafter the FWHM value decreased rapidly. The maximum depth of the layer with the dislocation density is about $0.21 \mathrm{~mm}$.
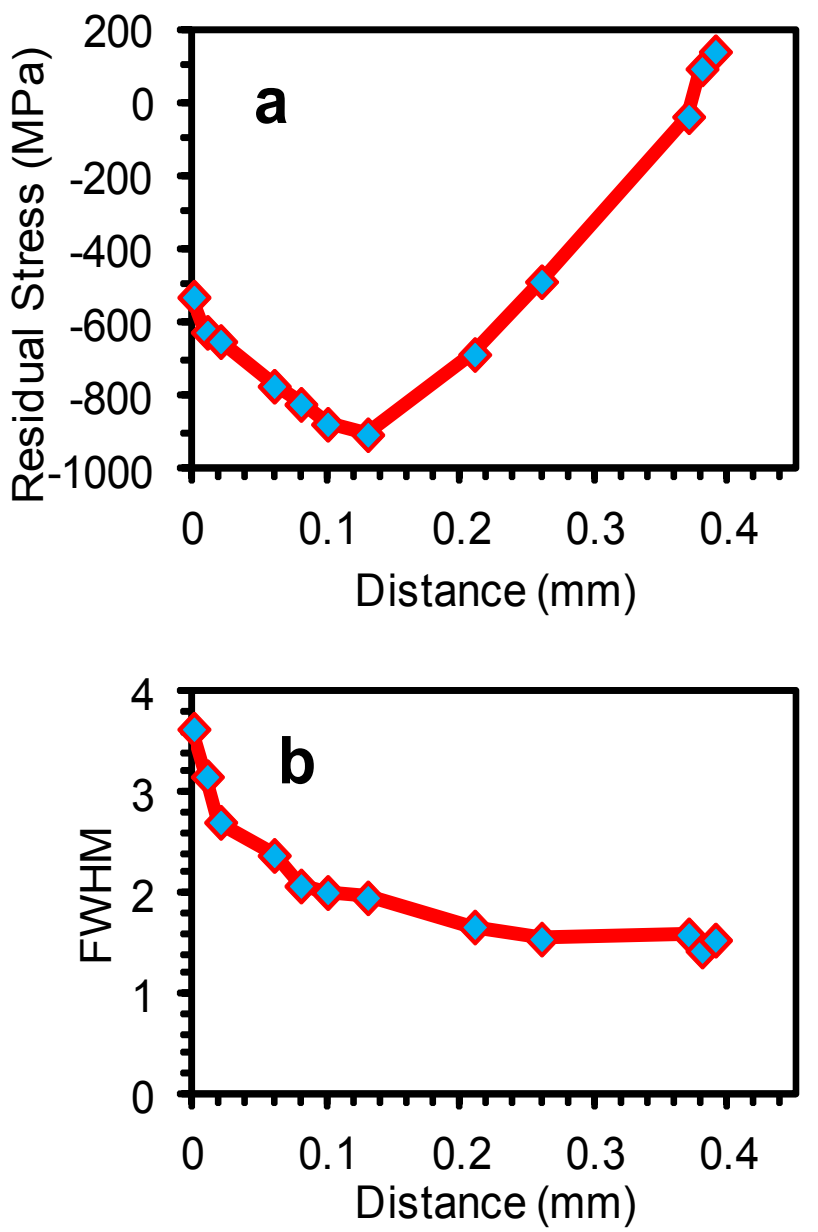

Figure 3. Evolution of the residual stress and FWHM from surface to inner of the TC21 alloy after shot peening. (a) Residual stress; and (b) FWHM. 


\section{Microstructure of the Surface Layer}

During the shot peening process, part of the energy was stored in the material, while most of the energy facilitates formation of dislocations. The dislocations are randomly distributed and they form dislocation boundaries. Large-area EBSD orientation maps can show clearly the distribution of the dislocation density along the distance from the surface. Figure 4 gives the percentage of deformed area in the subsurface layer of the shot peened region. This was obtained by analyzing the area of grains with high misorientations (including low-angle boundaries) inside the reference area of $460 \times 360 \mu \mathrm{m}$ using the option available in the EBSD analysis software TSL. Different colours mean different orientations in Figure 4(a). Figure 4(b) shows the boundary maps obtained after the boundary rebuilt by Orientation Imaging Microscopy (OIM) scanning area. The red lines indicate the $0-10^{\circ}$ low-angle boundaries; blue lines, $10-15^{\circ}$ boundaries; and black lines, $>15^{\circ}$ high-angle boundaries.

While geometry of the deformation depends on the shot peening energy, the lattice rotation solely depends on the evolution of the elastic part. Shot peening direction is on the righthand side of the Figure 4, which shows that there are few obvious changes of the crystal orientation and grain shape of the TC21 alloy. Moreover, analysis of the orientation map could not to provide any evidence of preferential texture in the surface layer. However, a strong gradient change of the dislocation density was observed in the shot peened surface layer. In the corresponding boundary map (Figure $4 \mathrm{~b}$ ), it is found that the deformation width is approximate $360 \mu \mathrm{m}$ which is consistent

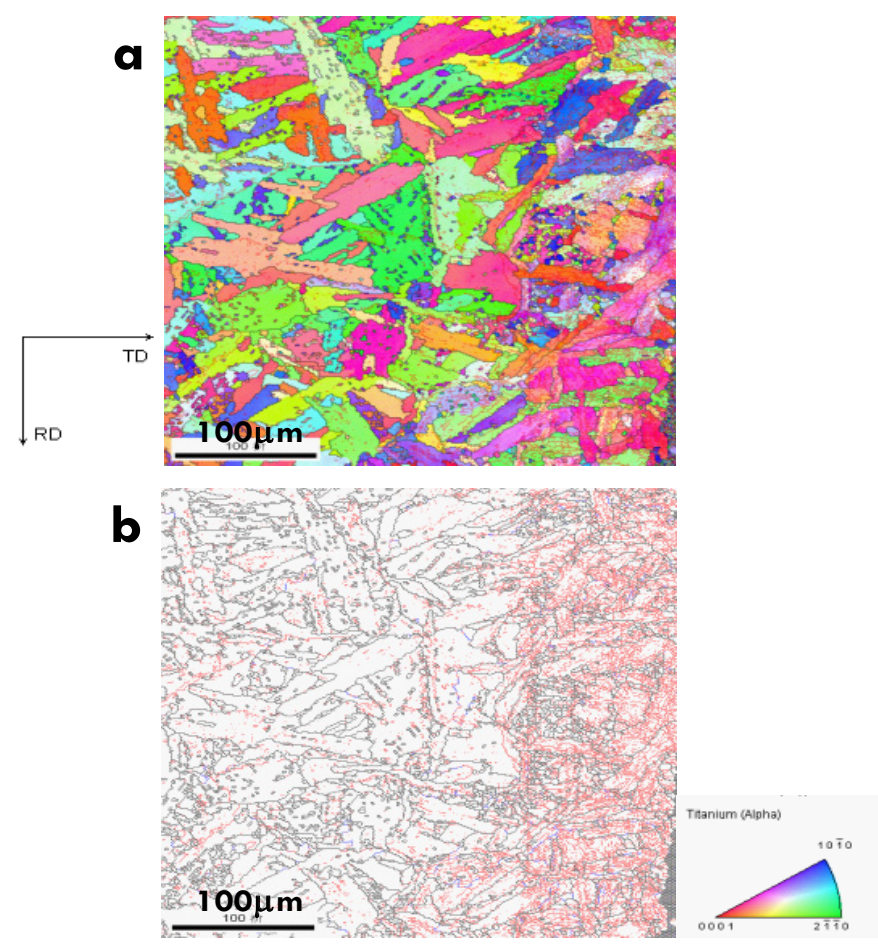

Figure 4. Orientation and boundary maps of the TC21 alloy after the high pressure shot peening. (a) Orientation map; (b) boundary map. with top surface observations, and the depth of significant plastic deformation is about $100 \mu \mathrm{m}$ in the peened surface layer. Higher density dislocations formed at the thickness of $100 \mu \mathrm{m}$ below the surface.

For the boundary analysis, Table 1 shows the number, length and distribution of the boundaries. The results show that the number and length of the boundary at the thickness of 100 $\mu \mathrm{m}$ below the surface is significantly higher than that at 100$360 \mu \mathrm{m}$ thickness. Especially, the number of the $0-10^{\circ}$ angle boundaries is the highest while the number of the $10-15^{\circ}$ angle boundaries is lower. It means that the increase of the boundary is mainly due to the low-angle dislocation boundary $(59.3 \%)$ in the surface layer after shot peening, and the percent of high angle boundary $(38.8 \%)$ is lower.

Table 1. Grain boundary results of the TC21 alloy after shot peening.

\begin{tabular}{lcccc}
\hline Distance & Angle & Number & Length & Fraction \\
\hline All & $0-10^{\circ}$ & 32477 & 28.1 & 0.419 \\
& $10-15^{\circ}$ & 1351 & 1.17 & 0.017 \\
& $15-180^{\circ}$ & 43619 & 37.8 & 0.563 \\
\hline $100 \mu \mathrm{m}$ from & $0-10^{\circ}$ & 22839 & 19.8 & 0.593 \\
the surface & $10-15^{\circ}$ & 751 & 0.65 & 0.019 \\
& $15-180^{\circ}$ & 14929 & 12.9 & 0.388 \\
\hline $100-360 \mu \mathrm{m}$ & $0-10^{\circ}$ & 10904 & 9.44 & 0.262 \\
from the & $10-15^{\circ}$ & 641 & 0.555 & 0.015 \\
surface & $15-180^{\circ}$ & 30031 & 26 & 0.722 \\
\hline
\end{tabular}

The microstructure of the TC21 alloy annealed at $910{ }^{\circ} \mathrm{C}$ $+550{ }^{\circ} \mathrm{C}$ is basket-weave like structure, composed of $\alpha$ phase with low-density dislocations and $\beta$ phase consisting of a lot of secondary $\alpha$ phase (shown in Figure 5). This type of microstructure can provide very attractive creep resistance and fracture properties, such as toughness and fatigue crack propagation resistance (Qu et al., 2005).

In deeper region from the shot peened surface, the structure shows a lot of single dislocations, dislocation arrays and single dislocation bands in $\alpha$ phase. Figure 6 and 7 show the dislocations microstructures at $0.5 \mathrm{~mm}$ from the surface.

The $\alpha$ phase has a hexagonal close-packed (hcp) structure and its original dislocations are always formed on the "a" plane $\{0001\}$. Its slip direction is [112 0] (Xu et al., 2008). When dislocations reach a boundary, they will form the dislocation arrays. Figure 6(a) shows two dislocation arrays in the $\alpha$ phase plate, as indicated by arrows. When the operation vector $\mathbf{g}=[1$ 011], the dislocation lines are visible clearly. However, when $\mathbf{g}=\left[1{ }^{-100}\right]$, the longer ones disappear, while the shorter ones are still visible. Therefore, the Burgers vector of the longer dislocations is $\mathbf{b}=1 / 3[112 \overline{0}]$, and the shorter ones, $\mathbf{b}=1 / 3[1 \overline{2} 1 \overline{0}]$. From the Berghzan map of the hcp phase, these two arrays are the OC type "a" plane dislocations. Figure 6(b) is enlarged from (a), showing that the three boundary dislocations in the $\alpha$ phase possess $\mathbf{b}=1 / 3[2-113]$ and those dislocations are the OB type. In the titanium with lattice parameter ratio of $c / a=1.533$, dislocations can be formed on $\{0001\},\{101 \overline{0}\}$ and $\{101 \overline{1}\}$. Compared to the other hcp type materials, the increase of the slip planes can improve the deformation characterization of the material.

Figure 7(a) shows the single dislocation microstructure 

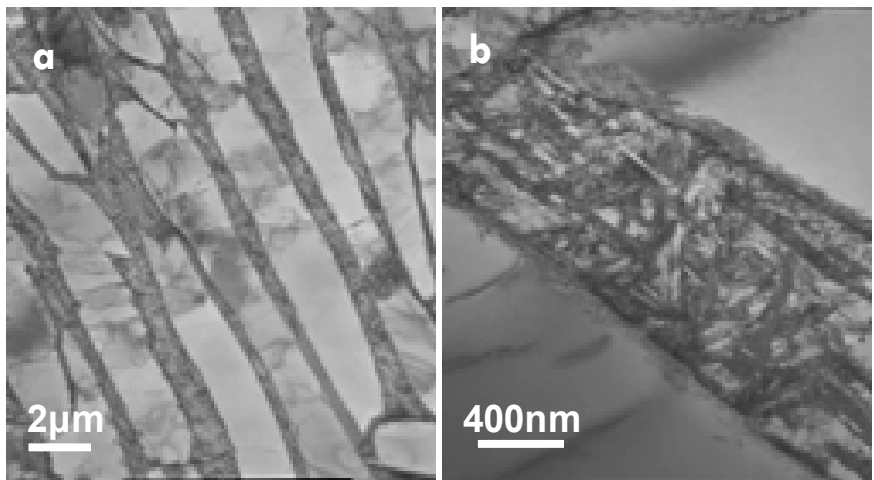

Figure 5. Net structure of the TC21 alloy. (a) $\alpha+\beta$ structure; (b) $\beta$ phase.

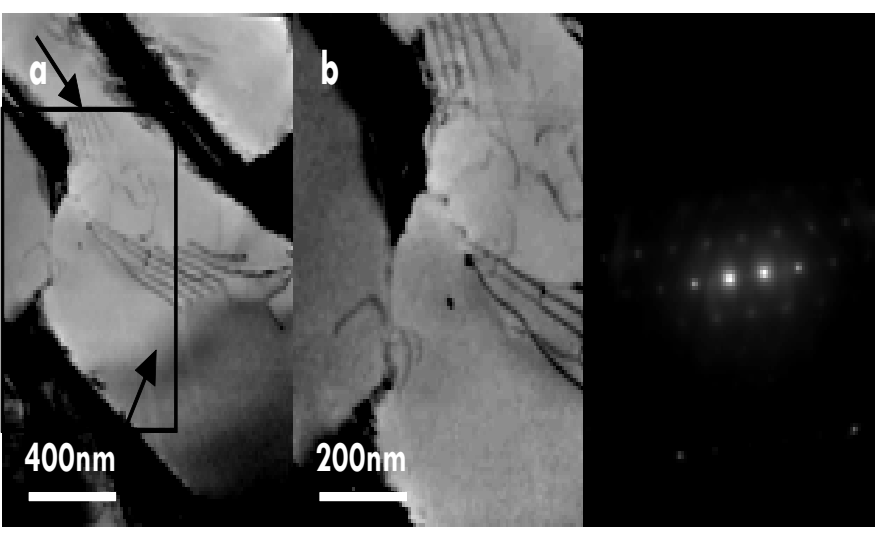

Figure 6. Dislocations in the $\alpha$ phase at $0.5 \mathrm{~mm}$ thickness. (a) Bright field image; (b) magnified image; (c) operation vector $\mathbf{g}=[1 \overline{0} 11]$.
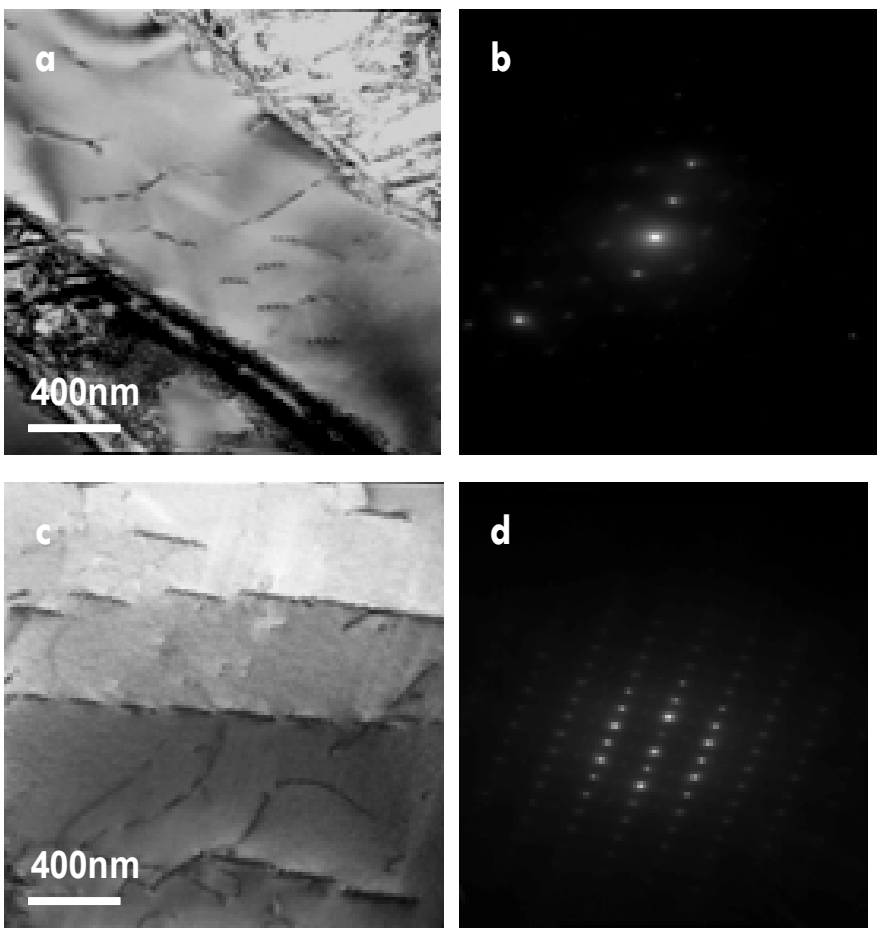

Figure 7. Dislocations in the $\alpha$ phase at $0.5 \mathrm{~mm}$ thickness. (a) Single dislocations; (b) $\mathbf{g}=[21 \overline{1} \overline{0}]$; (c) Single dislocation bands; (d) $\mathbf{g}=[1$ 011].
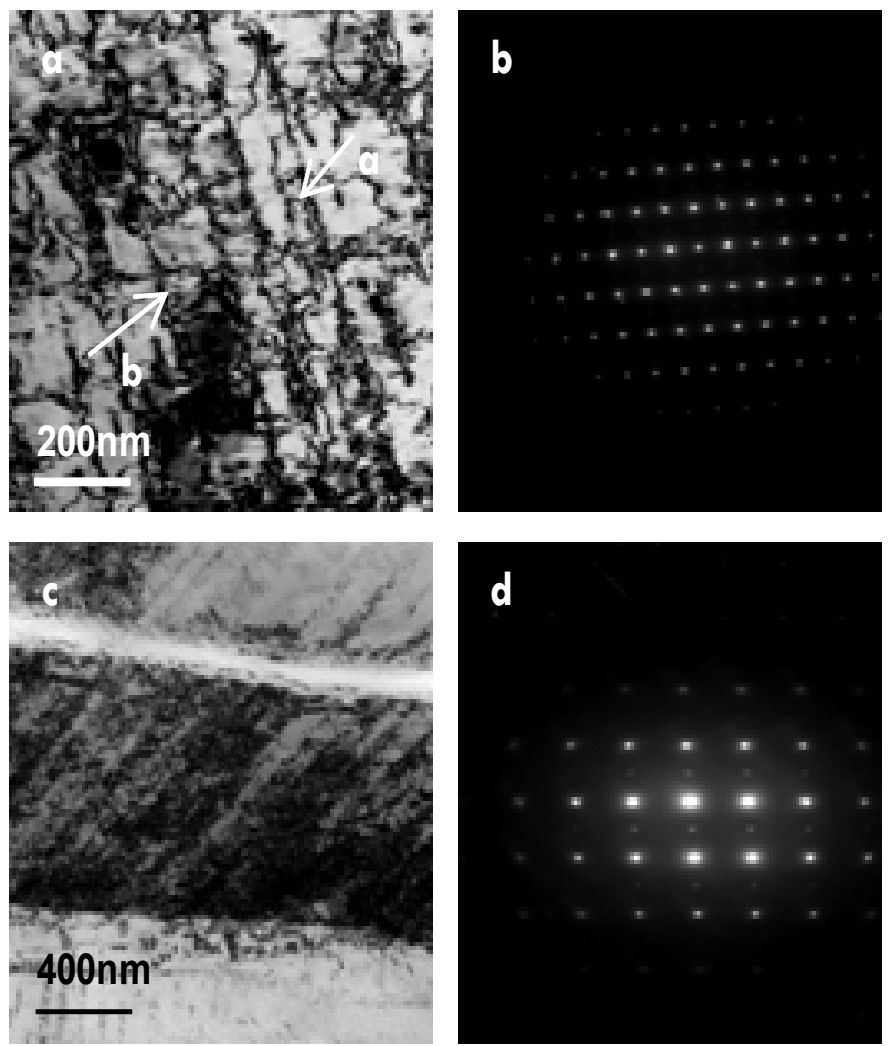

Figure 8. Dislocation bands in the $\alpha$ phase after shot peening at 50 $\mu \mathrm{m}$ thickness. (a) Dislocation bands; (b) electron diffraction pattern along [ $\left.\begin{array}{lll}21 & 1 & 0\end{array}\right]$; (c) dislocation band; (d) electron diffraction pattern along [101ㄹ]

along the $[112 \overline{3}]$ direction, in which a plane dislocations possess $\mathbf{b}=1 / 3<112 \overline{0}>$. Along the $\left[2 \overline{1}^{\overline{1}} \overline{0}\right]$ direction in the Figure 7(c), single dislocation band structure is observed in the $\alpha$ phase. Its diffraction pattern is shown in Figure 7(d). The slip plane is $\{0001\}$ "a" plane of the hcp structure, because single dislocations were formed to release the energy of the material. Afterwards, the dislocations will form the dislocation boundaries and subgrain boundaries. Dislocation network structure is not found at the $0.5 \mathrm{~mm}$ thickness from the surface. These results demonstrate that the dislocations are primarily planar dislocations at this thickness.

Figure 8 shows the classical dislocation structure at $50 \mu \mathrm{m}$ from surface. It is found that dense dislocation networks are formed, which are composed of dislocation bands and lots of single dislocation lines between the bands. In the [21 $\overline{1} \overline{0}]$ and [21 $\left.1 \overline{1}^{1}\right]$ directions, the dislocation bands formed in two directions, as indicated with a and $\mathrm{b}$ in Figure 8(a). The a band is formed on $\{0001\}$ base plane and the $\mathrm{b}$ band, on the $\{101 \overline{0}\}$ plane. Figure 8(c) shows another dislocation bands on the $\{101$ 1) plane.

In the shot peening process, the dislocation networks composed of dislocation bands in the $\alpha$ phase plate. This type of microstructure is the obstacle for the crystal deformation, and therefore it increases the fatigue strength of the material. There are no twins and stacking faults observed in the surface layer. 


\section{Discussion}

The results of this work clearly indicate the great benefits of shot peening on the TC21 alloy, by the formation of a favorable surface integrity within $370 \mu \mathrm{m}$ of the surface, coupled microstructurally with a work hardened near-surface layer. This transformation is promoted by the high-velocity deformation in the shot peening processing.

Based on experimental results, the surface integrity state of the TC21 alloy can be modified by shot peening with $0.4 \mathrm{~A}$ shot peening intensity. The peening energy was stored in material to create dislocations. The shot peening processing induced a lot of dislocations on the a plane, c plane and a/c plane, as shown in Figures 6 and 7. To decrease the energy of the material, the dislocations rebuilt and formed the band structure in the $\alpha$ phase plate near the surface. The typical microstructure is the net type composed of the bands, as shown in Figure 8(a) and (c). This microstructure increases the stored energy of the TC21 alloy and improves the resistance of deformation of the TC21 alloy. These results clearly imply that the strength of the surface material is higher than the unpeened specimen, and such a strength decreases with the distance from the shot peened surface. The shot peening deformation induced the increase of the compressive residual stress (Figure 2a) and hardness (Figure 3b) of the surface material. Also, both the stress and the hardness decrease with the distance from the surface.

Half-width profile of the diffraction line (Figure $3 \mathrm{~b}$ ) as well as the dislocation density profile (Figure $4 \mathrm{~b}$ ) of the shot peened TC21 alloy have the yield plastically deformed layers of 0.15 $0.20 \mu \mathrm{m}$. Corresponding to the residual stress distribution, the higher plastically deformation zone is within the surface and the maximum value of residual stress is $-903.5 \mathrm{MPa}$ at about $0.13 \mathrm{~mm}$ below the surface. At $0.13 \mathrm{~mm}$ to $0.37 \mathrm{~mm}$ thickness, the zone is a higher elastic deformation zone with lower degree of plastic deformation. As compared with the bulk material (Figure 6 and 7), the microstructure shows a lot of single dislocations, dislocation arrays and the single dislocation bands in $\alpha$ phase with higher dislocation density and the residual stress level.

As the Ra values increase, the stress concentration coefficient is higher and the fatigue life is very sensitive to the surface roughness. Some researchers (Gao et al., 2003; Lindemann et al., 2006) found that the compressive layers are deep and strong enough, so the damaging effects of notches and flaws are shifted to subsurface regions. Under these conditions, the fatigue behaviour is largely governed by the residual stress distribution and the relevant deformation mechanisms occurred in the surface layer.

The work hardening primarily retards crack initiation, and it is especially effective if the fatigue damage process is crack initiation controlled (Nalla et al., 2003). Moreover, the beneficial effect on fatigue life is very pronounced due to the high hardness, residual stress and dense dislocation structure of the shot peened surface. The fatigue test of the TC21 alloy after shot peening will be reported in a following paper.

\section{Conclusions}

The effects of shot peening on surface condition and structural evolution in the TC21 alloy have been investigated. After shot peening with $0.4 \mathrm{~A}$, the surface layer has been significantly changed. The hardness of the TC21 alloy increases about 2 times than that of the unpeened specimen, and the depth of the deformed layer with the residual stress is determined as 0.37 $\mathrm{mm}$.

In the deformed layer, there are no significant changes of crystalline phases. The structure of the shot peened layer is composed of dense dislocation networks, as shown by the EBSD method. The dislocations formed in the a, $\mathrm{c}$ and $\mathrm{a} / \mathrm{c}$ planes of $\alpha$ phase in the surface layer of the TC21 alloy after the shot peening. This microstructure can improve the resistance of deformation and increase the fatigue strength.

\section{References}

Baragetti S, M Guagliano (1998) Influence of low-intensity shot peening on the fatigue strength of an Al/Al. Fatigue Fract Eng Mater Struct 21 (6) 717-726.

Barry N, SV Hainsworth, ME Fitzpatrick (2009) Effect of shot peening on the fatigue behaviour of cast magnesium A8. Mater Sci Eng A 507 (1-2) 50-57.

De Los Rios ER, M Trull, and A Levers (2000) Modelling fatigue crack growth in shot-peened components of Al 2024-T351. Fatigue Fract Eng Mater Struct 23 (8) 709-716.

Fei Y, L Zhou, H Qu, Y Zhao, and C Huang (2008) The phase and microstructure of TC21 alloy. Mater Sci Eng A 494 (1-2) 166-172.

Feng, L, H Qu, Y Zhao, H Li, Y Zhang, and W Zeng (2004) High temperature deformation behavior of TC21 alloy. J Aeronaut Mater 24 (4): 11-13.

Gao YK, F Lu, YF Yin, M Yao (2003) Effects of shot peening on fatigue properties of $0 \mathrm{Cr} 13 \mathrm{Ni} 8 \mathrm{Mo} 2 \mathrm{Al}$ steel. Mater Sci Technol 19 (3) 372-374.

Ge P, Y Zhao, L Zhou (2005) Strengthening mechanism in $\beta$ titanium alloy. Mater Rev 19 (12) 52-56.

Harada Y, K Fukaura, S Haga (2007) Influence of microshot peening on surface layer characteristics of structural steel. J Mater Process Technol 191 (1-3) 297-301.

Jiang XP, CS Man, MJ Shepard, T Zhai (2007) Effects of shot-peening and re-shot-peening on four-point bend fatigue behavior of $\mathrm{Ti}-$ 6Al-4V. Mater Sci Eng A 468-470 (1) 137-143.

Lindemann J, C Buque, F Appel (2006) Effect of shot peening on fatigue performance of a lamellar titanium aluminide alloy. Acta Mater 54 (4) 1155-1164.

Luong H, MR Hill (2010) The effects of laser peening and shot peening on high cycle fatigue in 7050-T7451 aluminum alloy. Mater Sci Eng A 527 (3) 699-707.

Nalla RK, I Altenberger, U Noster, GY Liu, B Scholtes, RO Ritchie (2003) On the influence of mechanical surface treatments-deep rolling and laser shock peening-on the fatigue behavior of Ti-6Al$4 \mathrm{~V}$ at ambient and elevated temperatures. Mater Sci Eng A 355 (1-2) 216-230.

Okolo B, F Pérez-Willard, J Hawecker, D Gerthsen, A Wanner (2007) Focused ion beam study of the effects of shot peening on the subsurface microstructure of normalized pearlitic steel. J Mater Proc Technol 183 (2-3) 160-164.

Qu HL, YG Zhou, L Zhou, YQ Zhao, WD Zeng, L Feng, YQ Yang, 
J Chen, HQ Yu, H Li, YN Zhang, HC Guo (2005) Relationship among forging technology, structure and properties of TC21 alloy bars. Trans Nonferrous Met Soc China 15 (5) 1120-1124.

Shiozawa K, L Lu (2002) Very high-cycle fatigue behaviour of shotpeened high-carbon-chromium bearing steel. Fatigue Fract Eng Mater Struct 25 (8-9) 813-822.

Tönshoff HK, F Kroos, and C Marzenell (1997) High-Pressure Water Peening-a New Mechanical Surface-Strengthening Process. CIRP Ann-Manuf Technol 46 (1) 113-116.

Wagner L (1999) Mechanical surface treatments on titanium, aluminum and magnesium alloys. Mater Sci Eng A 263 (2) 210-216.
Wang R (1979) Effect of residual stresses of shot peening on the fatigue behaviour of a high strength steel. Fatigue Fract Eng Mater Struct 2 (4) 413-418.

Wu X, G Yang, P Ge, X Mao, B Feng (2008) Inductions of $\beta$ Titanium Alloy and Solid State Phase Transition. Titan Indu Progr 25 (5) 1-6.

Yamamoto T, T Takahashi, H Kimura, A Inoue (2007) Effect of ball-milling and shot-peening on $\mathrm{Zr}_{55} \mathrm{Al}_{10} \mathrm{Ni}_{5} \mathrm{Cu}_{30}$ alloys. J Alloys Compd 430 (1-2) 97-101.

Zhang X, D Liu (2009) Effect of shot peening on fretting fatigue of Ti811 alloy at elevated temperature. Inter J Fatigue 31 (5) 889-893. 